\title{
Vamos passear na floresta! 0 conforto térmico em fragmentos florestais urbanos
}

\author{
Let's take a walk through the forest! Thermal comfort in \\ urban forest fragments
}

\section{Cristiane Dacanal \\ Lucila Chebel Labaki \\ Talita Meulman Leite da Silva}

\section{Resumo}

$\mathbf{E}$

sta pesquisa investigou o papel dos fragmentos florestais urbanos no conforto térmico. Para tanto, foram monitoradas cinco localidades na cidade de Campinas (Brasil) durante o verão, outono e inverno de 2009. Os dados microclimáticos foram obtidos com o uso de uma estação meteorológica portátil, que mediu temperatura e umidade do ar, radiação, velocidade do vento e temperatura de globo. Além disso, aplicou-se questionários estruturados e fez-se observações de campo para a avaliação das condições de conforto térmico e da percepção ambiental dos usuários. Os índices PMV e PET foram calculados com o software RayMan 1.2 e comparados com os votos dados nas entrevistas. Os resultados indicam que os fragmentos florestais urbanos

Cristiane Dacanal Laboratório de Conforto Ambiental e Física Aplicada Faculdade de Engenharia Civil, Arquitetura e Urbanismo Universidade Estadual de Campinas Av. Albert Einstein, 951 Caixa Postal 6021 CEP 13083-852

Campinas - SP - Brasil Tel.: (19) 3521-2064 E-mail: crisdacanal@hotmail.com

Lucila Chebel Labaki Departamento de Arquitetura e Construção Faculdade de Engenharia Civil, Arquitetura e Urbanismo Universidade Estadual de Campinas

Tel.: (19) 3521-2384 E-mail: lucila@fec.unicamp.br

Talita Meulman Leite da Silva

Laboratório de Conforto Ambiental e Física Aplicada Faculdade de Engenharia Civil, Arquitetura e Urbanismo Universidade Estadual de Campinas Tel.: (19) 3521-2064 E-mail:

tameulman@yahoo.com.br

Recebido em 21/02/2010

Aceito em 26/04/2010 contribuem para o conforto térmico. A porcentagem de indivíduos sob condição de neutralidade térmica varia entre os índices: $72,4 \%$ consideravam-se confortáveis; $63,3 \%$ encontravam-se na faixa de temperatura PET entre $18{ }^{\circ} \mathrm{C}$ e $23^{\circ} \mathrm{C}$; e $39,8 \%$ estavam na faixa de conforto do PMV entre $-0,5 \mathrm{a}+0,5$. Os usuários percebem os bosques como locais confortáveis, o que é atribuído à presença da natureza. No entanto, notam problemas relacionados à conservação e à ocupação das áreas. $\mathrm{O}$ microclima específico da floresta, o ar fresco e a percepção de ar puro foram citados pela população e podem ser relacionados ao conforto ambiental.

Palavras-chave: Conforto térmico. Fragmento florestal urbano. Microclima. Percepção ambiental.

\section{Abstract}

This study investigated the role of urban forest fragments in thermal comfort. For that purpose, five different locations in the city of Campinas (Brazil) were monitored during the summer, autumn and winter of 2009. Microclimatic data were obtained with the use of a portable weather station that measured air temperature, air humidity, radiation, wind speed and globe temperature. In addition, structured interviews and field observations were carried out to evaluate the thermal comfort conditions and the occupants' perceptions of their environment. The PMV and PET indices were calculated by the RayMan 1.2 software and compared with the actual votes obtained through the interviews. The results indicate that urban forest fragments improve thermal comfort. The percentage of subjects reported as thermally neutral varied between indices: $72.4 \%$ were found comfortable, $63.3 \%$ were in the PET limit of $18-23^{\circ} \mathrm{C}$, and $39,8 \%$ were in the PMV range of -0.5 to +0.5 . Occupants perceived those places as comfortable, linking this to nature, but they also observed some problems regarding conservation and occupation. The specific forest microclimate, fresh air, and the perception of clean air were also cited by the population and can be linked to environmental comfort.

Keywords: Thermal comfort. Forest fragment. Microclimate. Environmental perception. 


\section{Introdução}

O processo de desmatamento brasileiro teve início já no período pré-colonial, intensificando-se durante a industrialização e a urbanização do país (1930-1970), concentrado principalmente nos Estados de São Paulo e Rio de Janeiro. O primeiro bioma a ser devastado foi a Mata Atlântica, ao longo da costa brasileira, restando atualmente pouco mais de $7 \%$ da floresta original, dividida entre matas primitivas e florestas secundárias (RBMA, 2009). Em Campinas, SP, cidade de desenvolvimento desta pesquisa, restam apenas $2 \%$ da vegetação original.

Em consequência da destruição sistemática das florestas, as cidades atuais possuem déficits de áreas verdes, restando pouco da vegetação nativa. A legislação de parcelamento do solo urbano no Brasil em vigor (BRASIL, 1979) exige apenas a reserva de uma faixa verde ao longo de córregos e a destinação de $35 \%$ de áreas públicas, que incluem circulação, equipamentos públicos de lazer, educação e saúde e espaços livres públicos em geral, mas não regulamenta sobre a qualidade dos espaços livres, que podem ou não ter vegetação arbórea com padrões de adensamento diferenciados. Dessa forma, a garantia de implantação ou conservação de florestas ocorre por meio do cumprimento da legislação florestal (BRASIL, 1965), que exige a reserva de área verde legal (20\% na maior parte dos biomas brasileiros) na transformação do uso da terra de rural para urbano, além da preservação ou reconstituição das matas de galeria.

Diante das mudanças globais e da necessidade de adesão ao paradigma do século XXI, o do desenvolvimento sustentável, reconhece-se a importância da preservação e da reconstituição das florestas no meio urbano, em benefício da conservação de espécies da fauna e da flora, do balanço hídrico e da qualidade da água, da qualidade do ar, do clima e, consequentemente, da qualidade de vida humana.

Neste artigo, foca-se a atuação do microclima de fragmentos florestais urbanos no conforto térmico. Tais fragmentos, apesar de sofrerem alta pressão antrópica e de não terem possibilidade de conexão com outras matas, desempenham forte função social, que pode estar relacionada às condições microclimáticas e aos seus aspectos físicos, possibilitando uma diversidade de funções. De um ponto de vista mais amplo, reconhece-se que a presença de florestas imbricadas no espaço urbano atua positivamente na eficiência energética das construções que as circundam. Nesse sentido, a pesquisa de campo tem como objetivos: (a) quantificar e descrever o conforto térmico em fragmentos florestais urbanos no Clima Tropical de Altitude de Campinas, SP; e

(b) descrever a percepção ambiental dos usuários em relação aos fragmentos florestais urbanos, a sensação térmica e o conforto térmico.

\section{Natureza e conforto térmico}

A temática do conforto térmico surgiu tendo em vista a necessidade de condicionamento de ambientes fechados para um melhor rendimento das atividades humanas, especialmente no trabalho. Mais recentemente, a busca de estratégias bioclimáticas para a melhoria da eficiência energética das edificações e a preocupação com a qualidade dos espaços livres públicos vieram a desencadear maior interesse no conforto térmico em espaços abertos. Diante disso, o elemento vegetação aparece como parte integrante do projeto urbano, reconhecendo-se sua importância na alteração das condições microclimáticas e, consequentemente, no desempenho térmico das construções, além da influência positiva no conforto térmico.

Pesquisas atuais revelam a dificuldade no estabelecimento de parâmetros para o conforto térmico em espaços abertos, devido às oscilações das variáveis climáticas e à variabilidade na composição dos espaços, dificultando o estabelecimento de réplicas para a realização de experimentos de campo. Além disso, a quantificação do "conforto" pelo homem é influenciada por fatores como a experiência térmica, a expectativa térmica, a adaptação térmica e a aliestesia (DACANAL et al., 2009; NIKOLOPOULOU; STEEMERS, 2003; SPAGNOLO; DE DEAR, 2003).

Alguns benefícios psicológicos das áreas verdes são apresentados por Miller (2007), tais como sentimentos de saúde, de paz e de serenidade, melhoria da autoestima, saúde física, restauração psíquica e mental, socialização, solidariedade, ensino e desenvolvimento das crianças, valores pessoais e sociais, liberdade e espiritualidade. Além disso, provêm à população oportunidades para lazer, descanso e sociabilidade, valorizam o entorno, contribuem para a vitalidade urbana e para a imagem da cidade (JACOBS, 2000; LYNCH, 1997; NIKOLOPOULOU, LYKOUDIS, KIKIRA, 2003; SPAGNOLO; DE DEAR, 2003).

Relacionando fatores comportamentais ao conforto térmico em espaços abertos, destacam-se as pesquisas realizadas por Nikolopoulou, Baker e Steemers (2001), que verificaram como o conforto 
térmico altera os padrões de uso em praças, ruas e parques no centro de Cambridge; Nikolopoulou, Lykoudis e Kikira (2003), que realizaram trabalho similar na Grécia; Nikolopoulou e Steemers (2003), que buscaram mensurar o impacto relativo dos parâmetros naturalidade, expectativas, experiência, tempo de exposição, controle percebido e estímulos ambientais no conforto térmico em espaços abertos; Spagnolo e De Dear (2003), que verificaram a aplicabilidade de alguns índices de conforto desenvolvidos para ambientes internos, como o PMV, em espaços abertos e semiabertos de Sidney, Austrália; Nikolopolou e Lykoudis (2006), que buscaram avaliar o conforto térmico em áreas livres urbanas em países europeus; Fontes, Aljawabra e Nikolopoulou (2008), que seguiram a mesma metodologia para avaliar as condições de conforto térmico na Queen Square, no centro histórico de Bath, Inglaterra; e Lin (2009), que no clima quente e úmido de Taiwan avaliou a influência dos fatores fisiológicos, psicológicos e comportamentais na adaptação térmica dos indivíduos em espaços abertos. Este autor verificou que a faixa de neutralidade térmica (percepção de conforto) em clima quente é maior que em clima temperado (90\% de conforto para a PET entre 21,3 e $28,5{ }^{\circ} \mathrm{C}$ ), ressaltando que os modelos de balanço de calor não são suficientes para explicar o conforto térmico em espaços abertos.

No Brasil, Gomes e Amorim (2003) monitoraram variáveis ambientais para cálculo da temperatura efetiva e avaliação de conforto térmico em praças com diferentes densidades de arborização na cidade de Presidente Prudente, SP. Trabalho mais recente com uma praça nessa mesma cidade foi realizado por Shimakawa e Bueno-Bartholomei (2009), que utilizaram uma metodologia adaptada do projeto RUROS, dentro do projeto "Conforto térmico em espaços públicos abertos: aplicação de uma metodologia em cidades do interior paulista", do qual também fazem parte Dacanal et al. (2009) e Brusantin e Fontes (2009), respectivamente em Campinas e em Bauru, SP. Abordando a influência da vegetação no conforto térmico em espaços abertos, Labaki et al. (2000) e Castro e Lima (1999) iniciaram pesquisas em bosques públicos de Campinas, SP.

Revisões de índices de conforto térmico em espaços abertos constam em Monteiro e Alucci (2006, 2007a, 2007b), Spagnolo e De Dear (2003). Especificamente sobre a PET citam-se Höppe $(1999,2002)$ e Matzarakis, Mayer e Iziomon (1999). Também destaca-se o trabalho de Matzarakis, Rutz e Mayer (2006), cujo software RayMan 1.2, baseado no Modelo RayMan, desenvolvido pelo Instituto Meteorológico da Universidade de Freiburg (2009), foi utilizado na presente pesquisa para cálculo da temperatura PET e índice PMV.

\section{Índices de conforto térmico para avaliação de espaços abertos}

A presente pesquisa utiliza dois índices calculados, o PMV (predicted mean vote) e a PET (physiological equivalent temperature), e um índice obtido empiricamente, o ASV (actual sensation vote).

O PMV (FANGER, 1972; ISO, 2005) é um índice baseado no balanço de calor do corpo humano com o ambiente, de modo que a sensação de conforto deve ocorrer quando a produção interna de calor do corpo for igual à perda de calor para o ambiente. $\mathrm{O}$ índice PMV resulta em uma escala de valores entre +3 e -3 , correspondentes a classes de sensação térmica, que variam entre muito calor (hot) e muito frio (cold) (ISO, 2005). Apesar das condicionantes que limitam a aplicação do PMV para a avaliação de conforto térmico em ambientes externos, optou-se por sua utilização, dado o domínio na interpretação desse índice por pesquisadores do mundo todo.

Já o PET é um índice desenvolvido para espaços abertos ou fechados, que representa uma temperatura fictícia, resultante da interação entre variáveis físicas e ambientais de um ambiente real. O esforço fisiológico de um indivíduo ao ar livre, realizando qualquer tipo de atividade, é comparado ao esforço do indivíduo padrão em ambiente controlado em que a única variável é a temperatura PET (HÖPPE, 1988, 1993, 1999).

A comparação entre as faixas de sensação e estresse térmico relacionadas aos índices PET e PMV encontram-se no Quadro 1.

Apesar de as condições térmicas dos ambientes influenciarem o uso dos espaços, a adaptação psicológica, a possibilidade de escolha, os estímulos ambientais, a experiência térmica, a memória e as expectativas têm grande peso no conforto térmico em ambientes externos. Assim, partindo-se do princípio da adaptabilidade do corpo ao ambiente térmico, também se utiliza o índice ASV, descrito por Nikolopoulou, Lykoudis e Kikira (2003) e por Nikolopoulou e Steemers (2003), que se trata de índice empírico, obtido por meio de questionário, para avaliar a sensação térmica dos indivíduos no momento da entrevista. Questões relacionadas à afetividade das pessoas para com o ambiente e possível influência de fatores psicológicos na atribuição do voto real de conforto também foram contempladas, aplicandose na pesquisa de campo os conceitos de espaço $e$ lugar e de topofilia (TUAN, 1980, 1983). 


\begin{tabular}{|c|c|c|c|c|}
\hline $\begin{array}{l}\text { PET (calibrado } \\
\text { por Monteiro e } \\
\text { Alucci, 2007) }\end{array}$ & $\begin{array}{c}\text { PET } \\
\text { (JENDRITZKY et } \\
\text { al., 1990 apud } \\
\text { MATZARAKIS et } \\
\text { al., 1999; } \\
\text { MATZARAKIS; } \\
\text { MAYER, 1997) } \\
\end{array}$ & $\begin{array}{l}\text { Sensibilidade } \\
\text { térmica }\end{array}$ & $\begin{array}{l}\text { Grau de estresse } \\
\text { fisiológico }\end{array}$ & PMV \\
\hline & & Muito frio & Estresse por frio extremo & \\
\hline \multirow[t]{2}{*}{$\angle 4{ }^{\circ} \mathrm{C}$} & $4{ }^{\circ} \mathrm{C}$ & & & $-3,5$ \\
\hline & & Frio & Estresse por frio forte & \\
\hline \multirow[t]{2}{*}{$<12^{\circ} \mathrm{C}$} & $8{ }^{\circ} \mathrm{C}$ & & & $-2,5$ \\
\hline & & $\begin{array}{l}\text { Frio moderado } \\
\text { (fresco) }\end{array}$ & $\begin{array}{c}\text { Estresse por frio } \\
\text { moderado }\end{array}$ & \\
\hline \multirow[t]{2}{*}{$<18^{\circ} \mathrm{C}$} & $13{ }^{\circ} \mathrm{C}$ & & & $-1,5$ \\
\hline & & Levemente frio & Estresse por frio leve & \\
\hline \multirow[t]{2}{*}{$18^{\circ} \mathrm{C}$} & $18^{\circ} \mathrm{C}$ & & & $-0,5$ \\
\hline & & Confortável & Sem estresse & \\
\hline \multirow[t]{2}{*}{$26^{\circ} \mathrm{C}$} & $23{ }^{\circ} \mathrm{C}$ & & & 0,5 \\
\hline & & Levemente aquecido & Estresse por calor leve & \\
\hline \multirow[t]{2}{*}{$>26^{\circ} \mathrm{C}$} & $29^{\circ} \mathrm{C}$ & & & 1,5 \\
\hline & & Aquecido & $\begin{array}{c}\text { Estresse por calor } \\
\text { moderado }\end{array}$ & \\
\hline \multirow[t]{2}{*}{$>31^{\circ} \mathrm{C}$} & $35^{\circ} \mathrm{C}$ & & & 2,5 \\
\hline & & Quente & Estresse por calor forte & \\
\hline \multirow[t]{2}{*}{$>43^{\circ} \mathrm{C}$} & $41^{\circ} \mathrm{C}$ & & & 3,5 \\
\hline & & Muito quente & $\begin{array}{c}\text { Estresse por calor } \\
\text { extremo }\end{array}$ & \\
\hline
\end{tabular}

Quadro 1 - Comparação de faixas de conforto térmico para espaços abertos

\section{Materiais e métodos}

\section{Clima de Campinas, SP}

Campinas situa-se no Estado de São Paulo, na latitude de $22^{\circ} 48^{\prime} 57^{\prime}$ ' Sul e na longitude de $47^{\circ}$ 03' 33" Oeste e altitude média é de $640 \mathrm{~m}$ (CEPAGRI, 2009). A classificação climática segundo a escala de Köepen é CWA (Clima Tropical de Altitude), com verão quente e chuvoso e inverno ameno e seco (BRASIL, 2008). A temperatura média anual é de $22,4{ }^{\circ} \mathrm{C}$, a média máxima ocorre no mês de fevereiro, $24,9{ }^{\circ} \mathrm{C}$, e a média mínima em julho, $18,5{ }^{\circ} \mathrm{C}$ (CEPAGRI, 2009).

\section{Apresentação das áreas de estudo}

A primeira etapa da pesquisa consistiu na identificação, escolha e caracterização de cinco áreas verdes públicas, classificadas como parques e bosques públicos pela Prefeitura Municipal de Campinas (Figura 1). A identificação das áreas verdes ocorreu consultando-se o Mapa de Vegetação Remanescente (CAMPINAS, 2006), parte integrante do Plano Diretor de Campinas, e a escolha delas decorreu da caracterização dos bairros aos quais pertencem, que deveriam ser de uso predominantemente residencial e com construções de baixo gabarito, com o intuito de homogeneizar as áreas de estudo e minimizar a interferência de variações climáticas dos bairros nas áreas verdes (OKE, 2006). Todos os bosques, apresentados nas Figuras de 2 a 11, possuem equipamentos comunitários, tais como playground, sanitários, bebedouros, espaços para atividades físicas, sede administrativa e alguns quadras esportivas. 


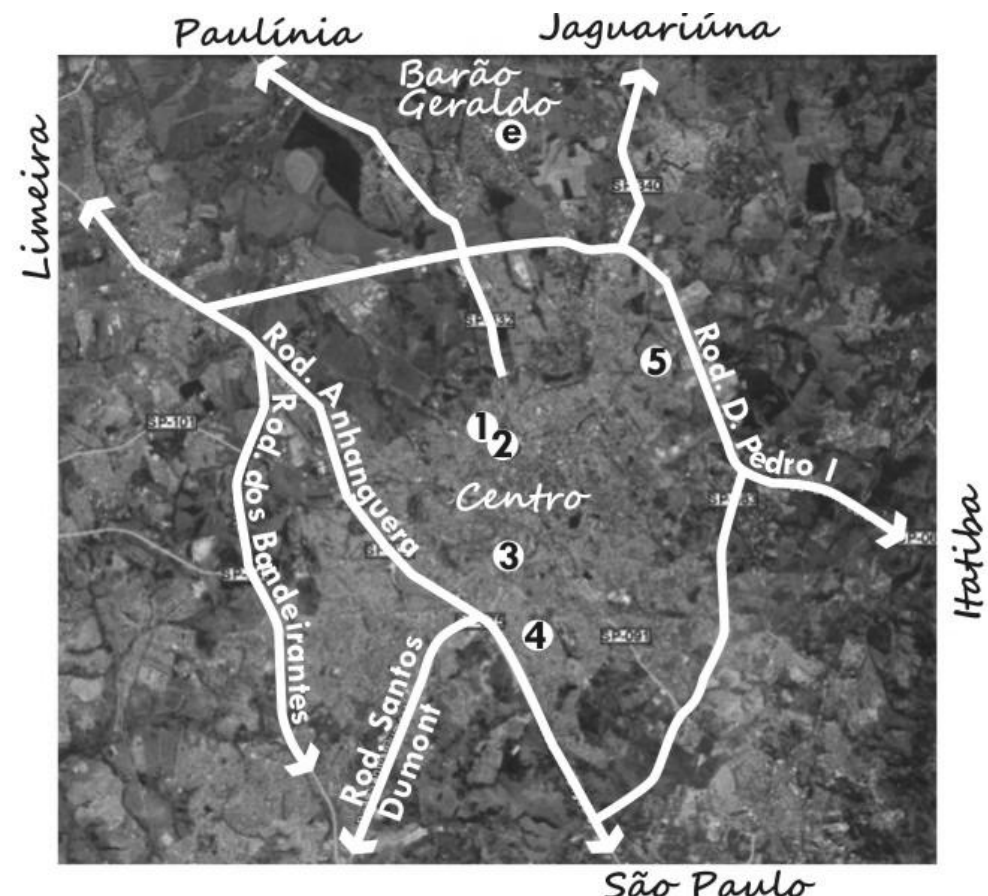

CAMPINAS, SP

Legenda

(e) Estação Meteorológica CEPAGRI

(1) Bosque dos Italianos

(2) Bosque dos Alemães

(3) Bosque São José

(4) Bosque dos Guarantãs

(5) Bosque da Paz

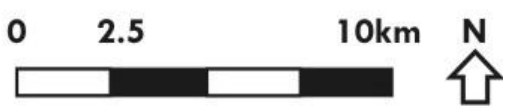

Figura 1 - Imagem aérea de Campinas com a localização das áreas de estudo

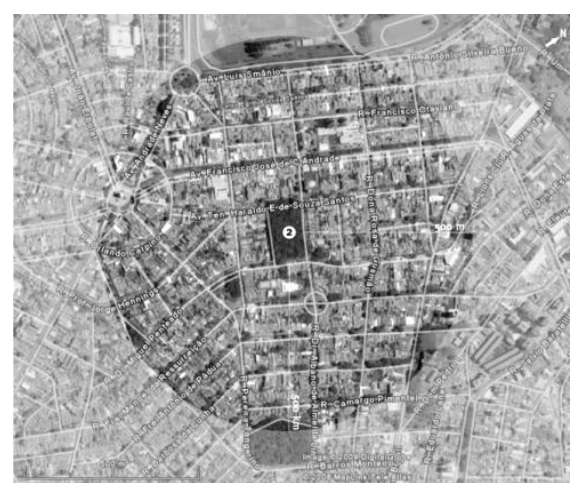

Nota: 22o 53' 22" Sul 47o 04' 39" Oeste; Altitude 736 m; Declividade 4,7\%; Exposição SE; A=1,40 há.

Figura 2 - Bosque dos Italianos

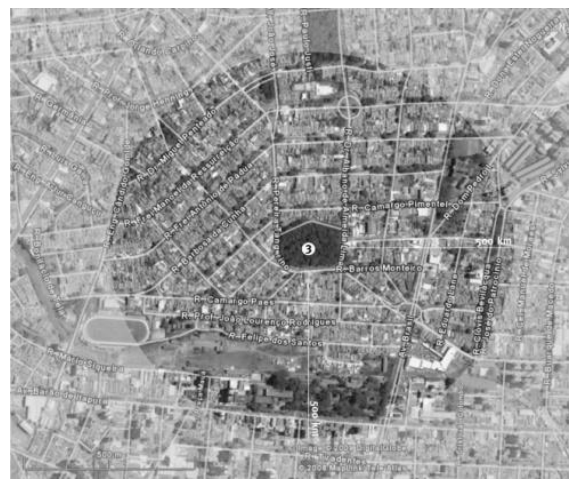

Nota: 22o 53' 41" Sul 47o 04' 10" Oeste; Altitude 695 m; Declividade 8,3\%; Exposição SE; $\mathrm{A}=2,0$ há.

Figura 4 - Croqui - Bosque dos Alemães

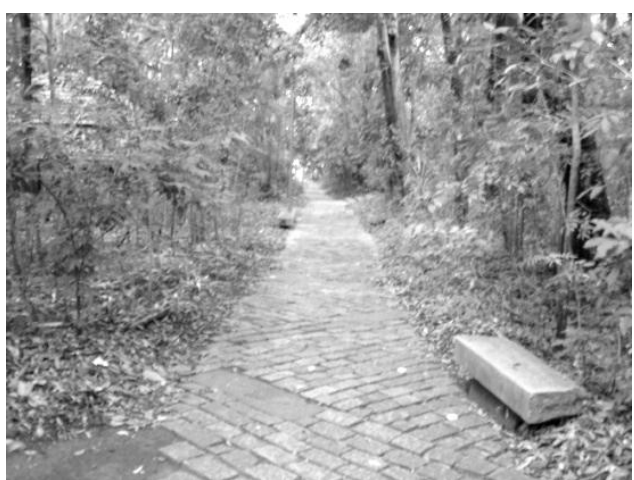

Figura 3 - Trilhas do Bosque dos Italianos

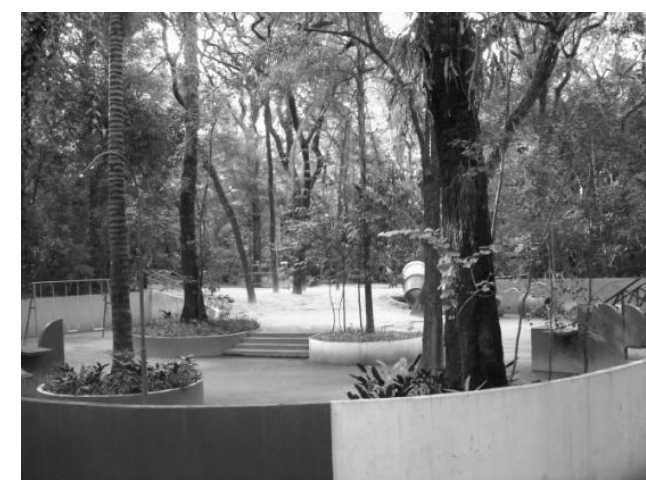

Figura 5 - Playground do Bosque dos Alemães 


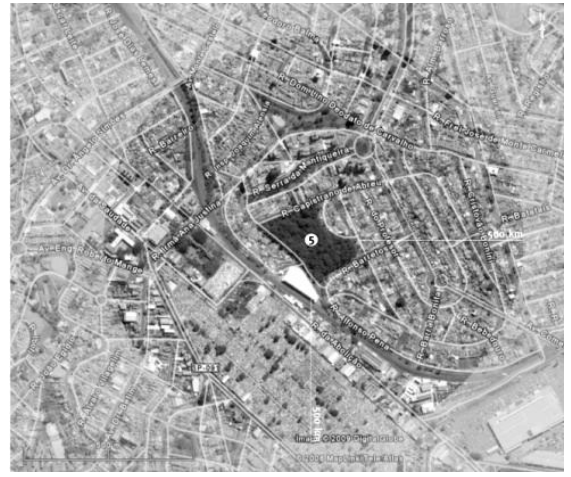

Nota: 22o 55' 30" Sul 47o 02' 76" Oeste; Altitude 699 m; Declividade 7,7\%; Exposição predominante $\mathrm{N} ; \mathrm{A}=3,36 \mathrm{ha}$, sendo 2,5 ha com vegetação.

Figura 6 - Bosque São José

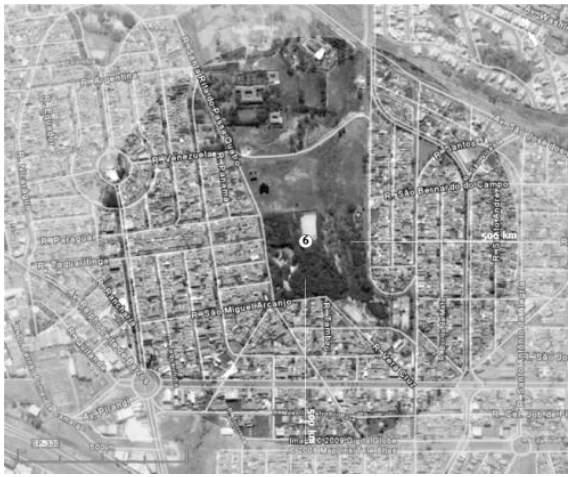

Nota: 22o 53' 22" Sul 47o 04' 39" Oeste; Altitude 716 m Declividade 5,1\%; Exposição SE; $A=8,71$ ha, sendo 4,38 ha com vegetação.

Figura 8 - Bosque dos Guarantãs

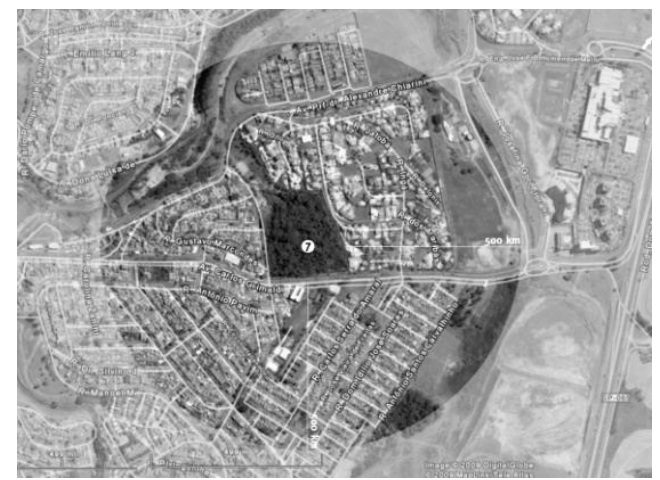

Nota: 22o 52' 26" Sul 47o 01' 77" Oeste; Altitude $636 \mathrm{~m}$ Declividade 16\%; Exposição predominante NO; $A=6,37$ ha, sendo 6,29 ha com vegetação.

Figura 10 - Bosque dos Paz

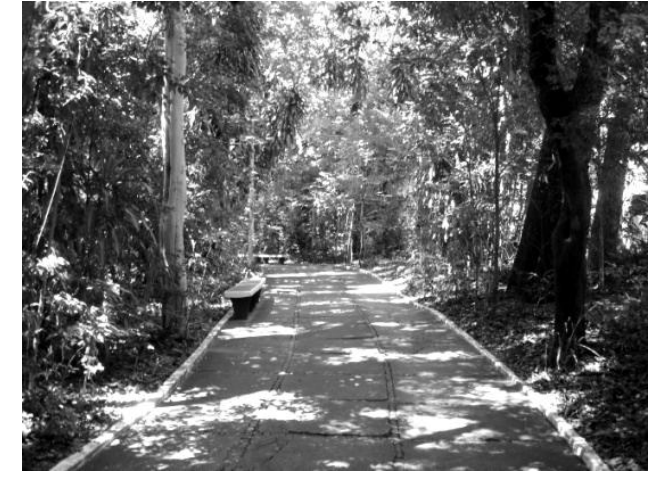

Figura 7 - Trilhas do Bosque São José

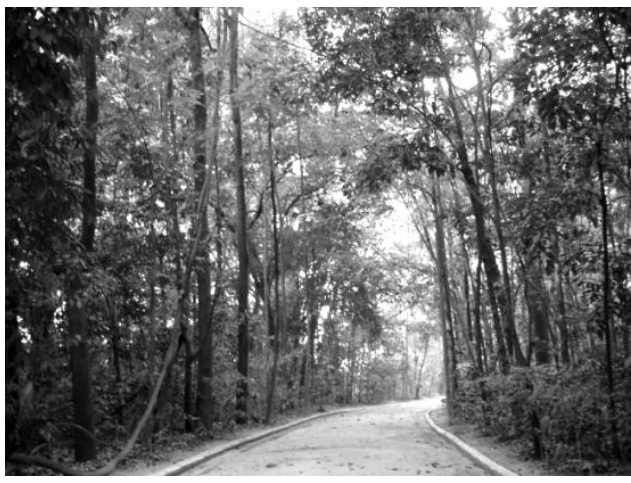

Figura 9 - Trilhas do Bosque dos Guarantãs

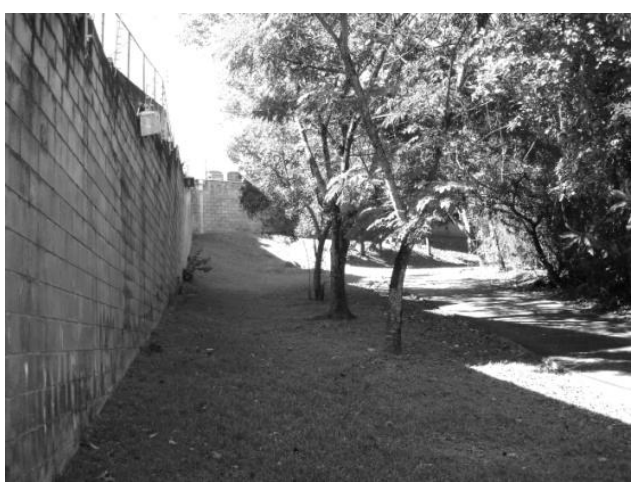

Figura 11 - Trilhas do Bosque da Paz, confrontando com um condomínio residencial 


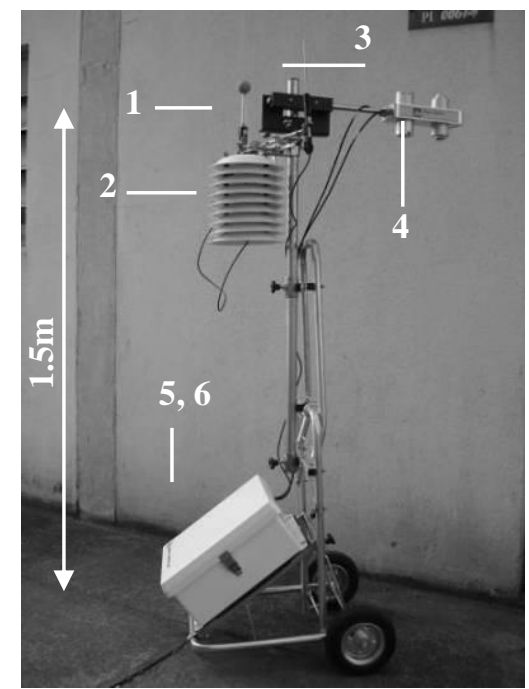

Figura 12 - Estação portátil com sensores numerados de 1 a 6

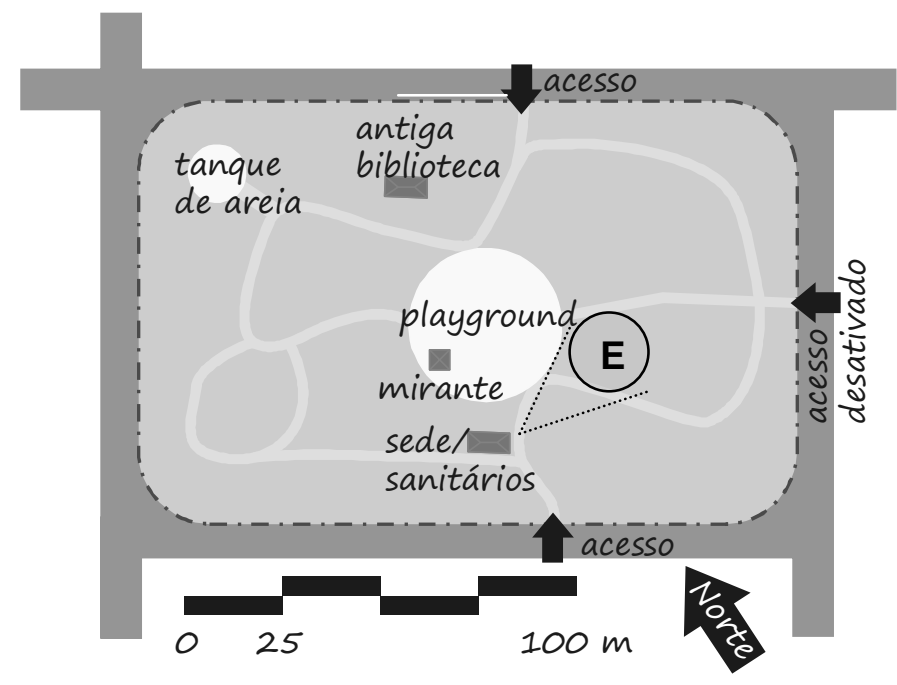

Figura 13 - Croqui com localização padrão da estação portátil (E) no interior dos fragmentos florestais. Situação do Bosque dos Italianos

\begin{tabular}{|l|l|l|}
\hline \multicolumn{1}{|c|}{ Equipamentos } & \multicolumn{1}{c|}{ Modelo/Precisão } \\
\hline 1 & $\begin{array}{l}\text { Sonda de temperatura ambiente para termômetro de globo. } \\
\text { Globo cinza, construído com bola de pingue-pongue oficial, } \\
\text { pintado na cor "cinza burguês" (e=0,9) }\end{array}$ & Testo 0613 1712 \\
\hline 2 & $\begin{array}{l}\text { Datalogger para registros de temperatura e umidade } \\
\text { protegidos por pratos, ventilados naturalmente }\end{array}$ & Testo 177-H1 \\
\hline 3 & Anemômetro omnidirecional, de esfera aquecida & Testo 0635 1549 \\
\hline 4 & Net Radiômetro, com piranômetro e pirgeômetro & Kipp \& Zonen 9 \\
\hline 5 & Coletor de dados & Campbell Scientific CR1000 \\
\hline 6 & Registrador multicanal & Testo 445 \\
\hline 7 & $\begin{array}{l}\text { Bússola de geógrafo, para direcionamento do Net } \\
\text { Radiômetro para norte }\end{array}$ & \\
\hline
\end{tabular}

Quadro 2 - Instrumentos de medição

\section{Monitoramento microclimático e questionário}

A segunda etapa da pesquisa, realizada entre janeiro e agosto de 2009, consistiu em monitoramentos microclimáticos das áreas e aplicação de questionários, baseando-se na metodologia do projeto RUROS - Rediscovering the urban and realm open spaces, realizado na Europa (NIKOLOPOLOU; LYKOUDIS, 2006). Para os monitoramentos microclimáticos utilizouse uma estação portátil (Figura 12), cujos sensores estão especificados no Quadro 2. A estação foi localizada no interior dos bosques, próximo à área da sede administrativa (Figura 13), com medições realizadas entre as $8 \mathrm{~h} 00$ e as $18 \mathrm{~h} 00$, em intervalos de $5 \mathrm{~min}$, em dias alternados entre os bosques, totalizando 22 dias de medições. O questionário baseou-se no padrão utilizado pelo projeto
RUROS, com algumas adaptações, sendo composto dos seguintes itens: Parte 1: gênero, idade, antropometria do entrevistado, atividade, escolaridade, resistência térmica das vestimentas; Parte 2: percepção do clima, microclima e condições de tempo; Parte 3: conforto térmico; Parte 4: imagem do lugar, motivos de uso, frequência de uso, problemas relacionados ao espaço, topofilia.

\section{Forma de análise dos resultados}

Utilizou-se o software RayMan 1.2 (UNIVERSITÄT FREIBURG, 2009) para cálculo dos índices de conforto térmico PMV e PET. Esse software permite a introdução de dados do indivíduo (atividade metabólica [W], resistência térmica das roupas [clo], gênero [m, f], idade, peso [kg] e altura [m]) e de dados climáticos 
(temperatura do ar $\left[{ }^{\circ} \mathrm{C}\right]$, umidade do ar [\%] ou pressão de vapor, velocidade do ar $[\mathrm{m} / \mathrm{s}]$ e radiação global $\left[\mathrm{W} / \mathrm{m}^{2}\right]$ ou $\operatorname{Trm}\left[{ }^{\circ} \mathrm{C}\right]$ ).

Os resultados foram analisados e discutidos em cinco partes:

(a) comparação entre as médias das variáveis microclimáticas obtidas no interior dos bosques públicos e as registradas na estação meteorológica da cidade de Campinas (CEPAGRI, 2009);

(b) frequência dos dados referentes ao perfil dos usuários dos bosques;

(c) frequência das categorias de respostas referentes à percepção do microclima nos bosques e das condições de tempo na ambiência urbana;

(d) frequência e distribuição dos índices PMV, PET e ASV; e

(e) categorização e frequência dos dados referentes à percepção ambiental, separados em motivos de uso, frequência de uso, imagem mental e problemas observados no espaço.

\section{Resultados}

\section{Microclima de fragmentos florestais urbanos}

O monitoramento microclimático foi realizado no período de verão (4 dias), outono (11 dias) e inverno (7 dias), alternadamente entre os cinco bosques públicos, com variações nas condições de tempo, buscando-se, contudo, a baixa nebulosidade. A Tabela 1 possibilita comparar as médias das variáveis climáticas dos bosques aos da estação meteorológica de Campinas (CEPAGRI, 2009) para os mesmos dias e horários monitorados (8h00-18h00 aproximadamente).

A média da temperatura média do ar no período de verão é $1,76{ }^{\circ} \mathrm{C}$ mais baixa nos bosques do que na estação meteorológica. No outono essa diferença aumenta para $2,76{ }^{\circ} \mathrm{C}$, e no inverno, para $2{ }^{\circ} \mathrm{C}$. A diferença entre as médias das temperaturas máximas torna ainda mais evidente o frescor do interior dos bosques, sendo a temperatura máxima do ar cerca de $2,86{ }^{\circ} \mathrm{C}$ mais amena nos bosques no período de verão, $3,17{ }^{\circ} \mathrm{C}$ no outono e $2,53{ }^{\circ} \mathrm{C}$ no inverno.

Para se comparar a umidade do ar entre os bosques e a estação meteorológica, converteu-se a umidade relativa $(\%)$ em umidade absoluta $\left(\mathrm{g} / \mathrm{m}^{3}\right)$, com o auxílio do software PSICROM 1.0. Apesar de a umidade relativa do ar ser evidentemente mais elevada nos bosques do que na estação meteorológica - esta diferença chega a $11,5 \%$ no inverno -, verifica-se que a umidade absoluta é, na verdade, maior na estação meteorológica do que no interior dos fragmentos florestais urbanos. Durante o verão e o outono, um metro cúbico de ar tem cerca de 1,50 g de vapor d'água a mais na Cepagri do que os bosques. Já na estação seca, de inverno, a umidade do ar tende a se igualar entre os locais.

A velocidade do ar no interior dos bosques é baixa e com baixa amplitude, devido à rugosidade da vegetação, alcançando um máximo de $1,52 \mathrm{~m} / \mathrm{s}$. $\mathrm{Na}$ estação meteorológica, em campo aberto, a velocidade do ar a $2 \mathrm{~m}$ acima do solo é em média $2,8 \mathrm{~m} / \mathrm{s}$ mais elevada que no interior dos bosques.

A taxa de radiação incidente é atenuada pela folhagem da vegetação, que se apresenta estratificada. Em alguns horários pontuais a radiação permeia a folhagem, atingindo níveis mais próximos ao solo, mas em média a radiação é atenuada em 95\%. Esse percentual foi calculado utilizando-se a Equação 1, sugerida por BuenoBartholomei e Labaki (2003), que consiste em uma regra de três simples, em que a atenuação solar é o percentual de radiação que foi interceptada pela folhagem de vegetação, não alcançando o ponto onde se localiza a instrumentação à sombra.

$A t=\left(S_{\text {sun }}-S_{\text {shade }}\right) \cdot 100 / S_{\text {sun }}$

Eq. 1

Onde:

$A t$ : atenuação da radiação solar (\%);

$S_{\text {sun }}$ : radiação total incidente na estação meteorológica $\left(\mathrm{W} / \mathrm{m}^{2}\right)$ obtida pelo radiômetro; e

$S_{\text {shade: }}$ radiação global no interior dos bosques $\left(\mathrm{W} / \mathrm{m}^{2}\right)$, obtida pelo net radiômetro.

Na comparação entre as variáveis climáticas dos fragmentos florestais urbanos e da estação meteorológica, verificou-se que a temperatura do ar é mais baixa no interior dos bosques, a umidade absoluta do ar é mais baixa, apesar de a umidade relativa ser mais elevada, a velocidade do ar é baixa e mais estável, e a radiação solar é atenuada significativamente. $\mathrm{O}$ microclima característico de espaços com densa vegetação é também estável ao longo do dia, contribuindo para o conforto térmico, como será verificado nas seções seguintes. 


\begin{tabular}{|c|c|c|c|c|c|c|c|c|c|c|c|}
\hline & & \multicolumn{3}{|c|}{$\operatorname{Tar}\left({ }^{\circ} \mathrm{C}\right)$} & \multicolumn{3}{|c|}{ U.Abs $\left(\mathbf{g} / \mathbf{m}^{3}\right)$} & \multirow{2}{*}{$\begin{array}{c}\begin{array}{c}\text { Var } \\
(\mathbf{m} / \mathbf{s})\end{array} \\
\text { Máxima }\end{array}$} & \multicolumn{3}{|c|}{ Radiação (W/m2) } \\
\hline & & Média & Máxima & Mínima & Média & Máxima & Mínima & & Média & Máxima & Mínima \\
\hline \multirow{2}{*}{ V } & B & 26,07 & 27,60 & 23,05 & 14,7 & 13,87 & 14,7 & 1,52 & 22,44 & 257,59 & 4,46 \\
\hline & $\mathbf{C}$ & 28,46 & 30,44 & 25,35 & 16,24 & 15,53 & 16,24 & 3,66 & 522,55 & 883,75 & 44,08 \\
\hline \multirow{2}{*}{$\mathrm{O}$} & B & 23,35 & 24,71 & 20,97 & 13,56 & 13,19 & 13,84 & 0,61 & 17,36 & 183,17 & 2,75 \\
\hline & $\mathbf{C}$ & 26,11 & 27,88 & 23,39 & 14,85 & 14,5 & 15,17 & 3,77 & 324,24 & 607,20 & 13,52 \\
\hline \multirow{2}{*}{ I } & B & 20,77 & 23,06 & 16,21 & 10,89 & 9,81 & 10,92 & 0,96 & 25,58 & 287,63 & $-3,70$ \\
\hline & $\mathbf{C}$ & 22,77 & 25,59 & 18,42 & 10,65 & 10,01 & 10,7 & 3,95 & 415,66 & 666,07 & 13,99 \\
\hline & & $\begin{array}{l}\text { a: } \\
\text { verão; } \\
\text { outono } \\
\text { nverno; } \\
\text { bosques } \\
\text { Cepagr }\end{array}$ & & & & & & & & & \\
\hline
\end{tabular}

Tabela 1 - Médias das variáveis climáticas em três estações do ano de 2009. Comparação entre os bosques públicos e a estação meteorológica de Campinas (Cepagri)

\section{Perfil dos usuários}

Foram aplicados 147 questionários, abordando-se visitantes e funcionários de cinco bosques públicos de Campinas. O número de visitantes diários é relativamente baixo, de modo que em muitos dias foi possível abordar $100 \%$ das pessoas, justificando-se a população reduzida, cujo perfil é apresentado a seguir.

\section{Idade, sexo e escolaridade}

O perfil dos entrevistados é constituído por uma maioria de jovens e adultos, entre 15 e 45 anos $(64 \%)$, distribuídos entre $52 \%$ de homens e $48 \%$ de mulheres. Os níveis de escolaridade concentram-se no ensino médio completo (45\%), havendo um baixo percentual de indivíduos com nível superior completo (19\%), tendo em vista que $75 \%$ da amostra têm mais que 25 anos de idade.

\section{Antropometria}

Foram amostrados idade, peso e estatura dos indivíduos (Tabela 2), e a área corporal foi estimada a partir dessas variáveis, utilizando-se a Equação 2 de DuBois e DuBois (1916):
$A C=\left(P^{0,425} \times H^{0,725}\right) \cdot 0,007184$

Eq. 2

Onde:

AC é a área corporal $\left(\mathrm{m}^{2}\right)$;

$\mathrm{P}$ é a massa corporal $(\mathrm{kg})$; e

$\mathrm{H}$ a altura $(\mathrm{cm})$.

\section{Atividades}

Para o cálculo dos índices PMV e PET no software RayMan 2.1, foi estimado o nível de atividade para cada indivíduo, multiplicando-se a taxa metabólica [W/m $\left.{ }^{2}\right]$ (ISO 7730:2005) pela área corporal de cada indivíduo, calculada através da Equação 2. As atividades predominantes e níveis metabólicos constam na Figura 14.

\section{Resistência térmica das vestimentas}

Os conjuntos de vestimentas mais utilizados, bem como a frequência de uso, constam na Figura 15. A resistência térmica dos conjuntos de roupas [clo] teve pouca variação entre as categorias masculina e feminina. A maioria dos usuários (44\%) vestia calça comprida, camiseta e tênis, o que soma 0,55 clo.

\begin{tabular}{l|c|c|c}
\hline \multicolumn{1}{c|}{ Estatística } & \multicolumn{3}{c}{ Parâmetros } \\
\hline & $\begin{array}{c}\text { Área corporal } \\
\left(\mathbf{m}^{\mathbf{2}}\right)\end{array}$ & Altura (m) & Peso (kg) \\
\hline Média da amostra & 1,79 & 1,68 & 71,3 \\
\hline Mediana da amostra & 1,79 & 1,69 & 70,0 \\
\hline Média p/ grupo de mulheres com 30 anos & 1,76 & 1,65 & 68,3 \\
\hline Média p/ grupo de homens com 30 anos & 1,90 & 1,77 & 75,9 \\
\hline
\end{tabular}

Tabela 2 - Dados antropométricos dos entrevistados 


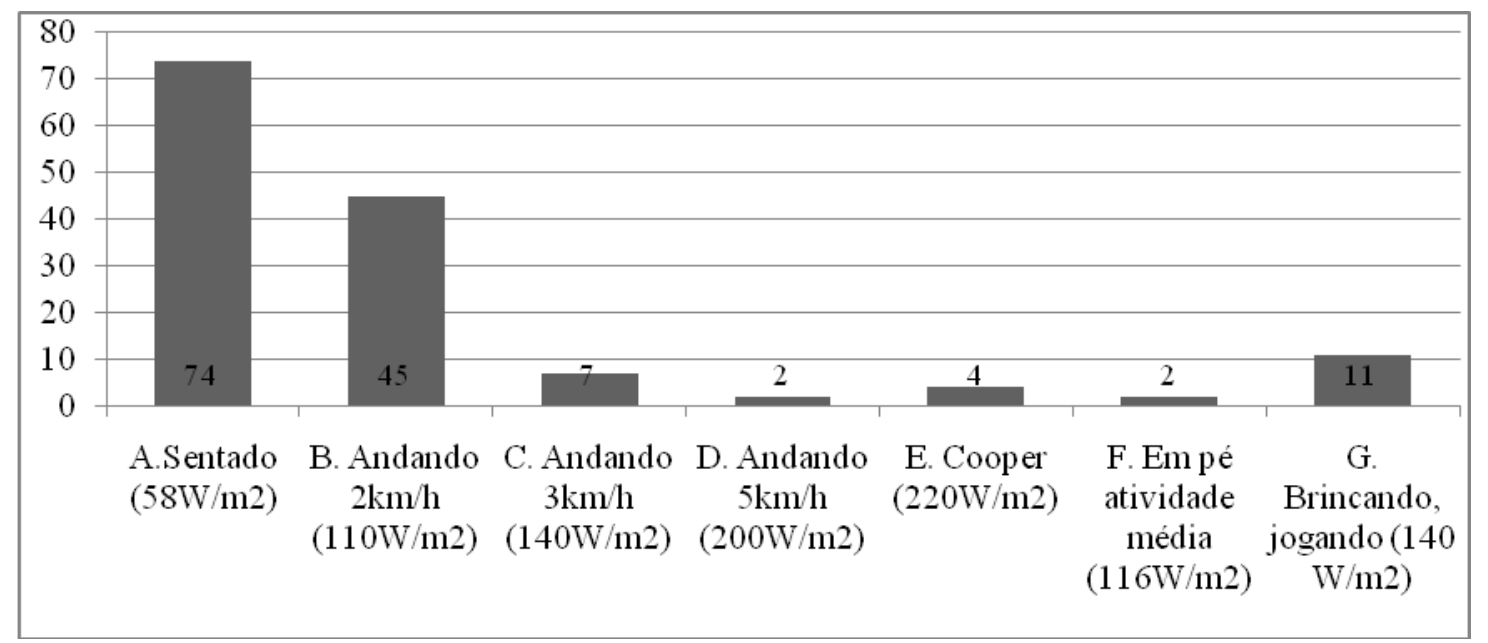

Amostra: 145 indivíduos.

Figura 14 - Frequência das atividades desenvolvidas e taxa metabólica (ISO 7730:2005)

\begin{tabular}{|c|c|c|c|c|c|}
\hline $\begin{array}{l}\text { Percentual de usuários vestindo os conjuntos } \\
\text { de vestimentas }\end{array}$ & $9 \%$ & $44 \%$ & $22 \%$ & $13 \%$ & $12 \%$ \\
\hline $\begin{array}{l}\text { Resistência térmica dos conjuntos de } \\
\text { vestimentas (clo) }\end{array}$ & 0,65 & 0,55 & 0,4 & 0,3 & 0,15 \\
\hline \multicolumn{6}{|l|}{$\begin{array}{l}\text { Vestimentas femininas } \\
\text { identificadas em campo }\end{array}$} \\
\hline \multirow{3}{*}{$\begin{array}{l}\text { Vestimentas masculinas } \\
\text { identificadas em campo }\end{array}$} & & ค & 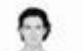 & $F$ & \\
\hline & & & & & \\
\hline & & & & $b$ & $\theta \varepsilon$ \\
\hline
\end{tabular}

Figura 15 - Frequência de conjuntos de vestimentas usados e resistência térmica (clo)

Houve baixa relação entre o nível de atividade do indivíduo $[\mathrm{W}]$ e a resistência térmica das vestimentas [clo]. Também houve pouca variação nos conjuntos de roupas usados ao longo das estações do ano. No entanto, a variação nos níveis máximos de atividade metabólica decresceu significativamente com o aumento do isolamento térmico das roupas: para 0,15 clo o maior nível de atividade metabólica encontrado foi $454 \mathrm{~W}$, e para 0,65 clo, foi $260 \mathrm{~W}$.

\section{Percepção do microclima e das condições de tempo}

A percepção ambiental consiste na consciência das sensações decorrentes da interação entre o homem e o espaço. Ela ocorre de maneira individualizada, visto que depende de experiências anteriores relacionadas às informações sensoriais, bem como à memória e à cultura. Nesse sentido, a percepção do microclima varia de acordo com as experiências climáticas já vividas pelo indivíduo e ocorre comparando-se o presente (espaço e tempo em que o corpo está presente) ao passado (mesmo espaço, porém em um tempo anterior) e a outros espaços (o aqui e o ali). Um encadeamento de perguntas pode conduzir o entrevistado a um processo dedutivo, conscientizando-o sobre a percepção do corpo em relação ao ambiente no momento presente, de maneira que os resultados de pesquisas em conforto térmico e sensação térmica sejam consistentes, minimizando a influência de fatores psicológicos 
nas respostas. Esse encadeamento de questões, sugerido e aplicado na presente pesquisa, está esquematizado na Figura 16.

Perguntou-se aos indivíduos sobre o clima da cidade de Campinas, em seguida como estava o tempo no dia do monitoramento na ambiência urbana, e por último sobre a sensação térmica e sobre o conforto térmico no interior dos bosques. A opinião sobre a sensação de cada parâmetro foi transcrita para uma escala categórica de cinco pontos, variando entre muito forte e muito fraco.
Assim, se uma pessoa considerou que o ar estava parado no dia monitorado, o voto para o parâmetro vento seria muito fraco.

A Figura 17 mostra a percepção das condições de tempo nos dias monitorados, a Figura 18 refere-se à percepção do microclima no interior dos fragmentos florestais, e a Figura 19 mostra a percepção do microclima dos indivíduos que se consideraram termicamente confortáveis no interior dos bosques ( $\mathrm{ASV}=0$ ).

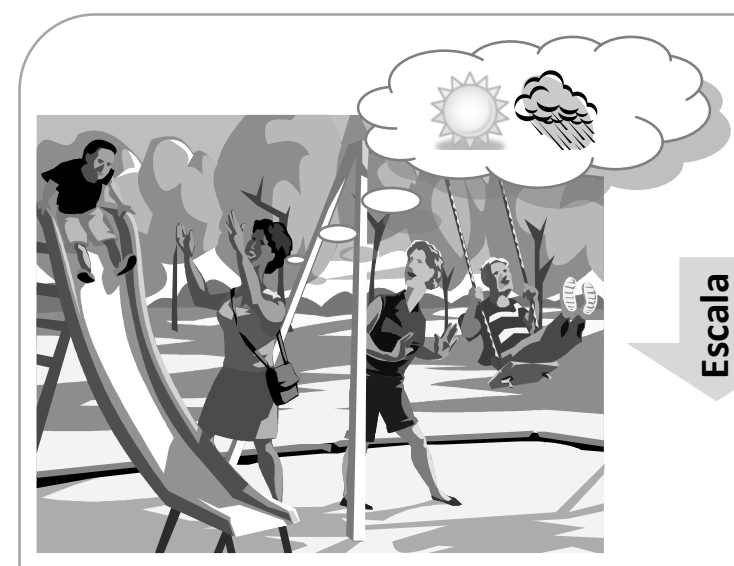

\section{Experiência térmica:}

Espaço vivido: vários

Tempo: passado

- Em vários espaços, situações vividas

- Na cidade avaliada

- No local avaliado

Percepção: vento, temperatura, umidade...

Espaço: a cidade, o bairro, o bosque, o indivíduo;

Tempo: presente

- Condições de tempo no dia monitorado

- Microclima no interior do bosque

- Estou confortável? Quanto?

Figura 16 - Percepção das condições climáticas a partir de inferências em relação à experiência térmica em diferentes escalas espaciais e temporais

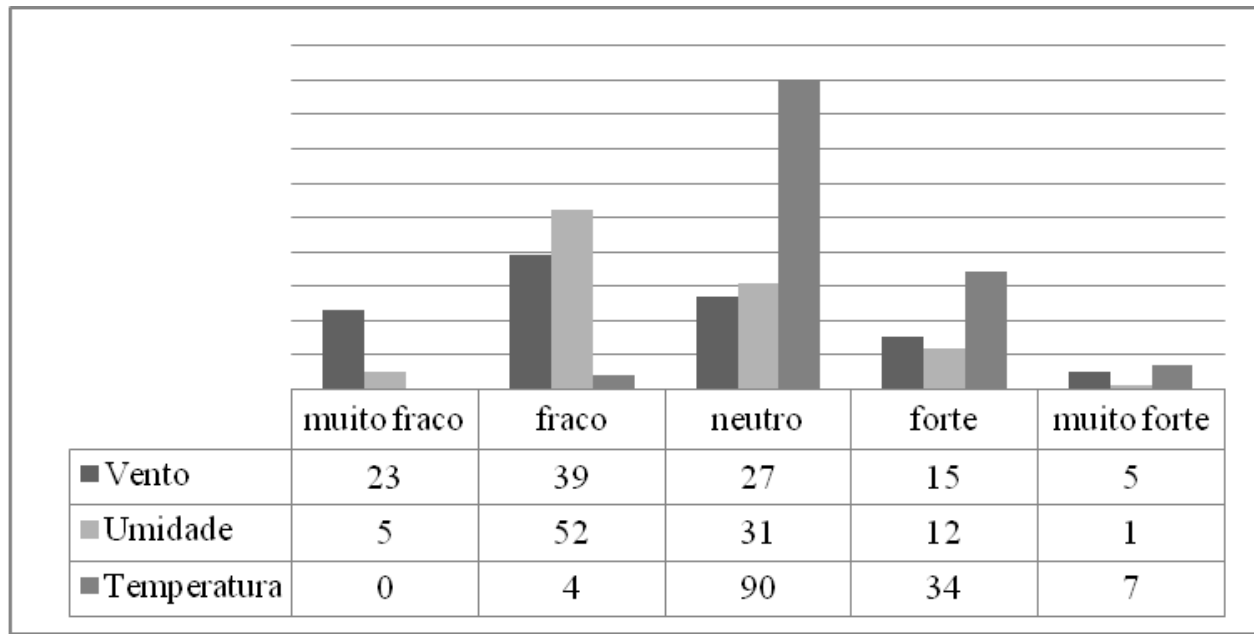

Figura 17 - Percepção das condições de tempo na ambiência urbana 


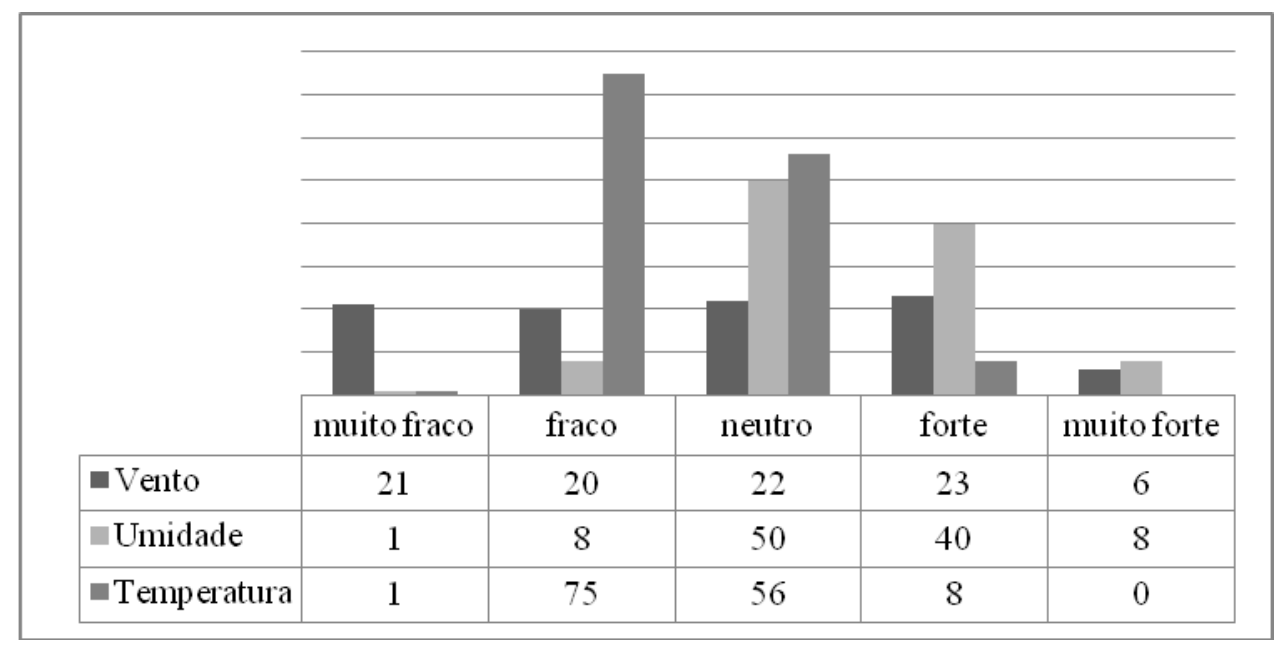

Figura 18 - Percepção do microclima no interior dos fragmentos florestais urbanos

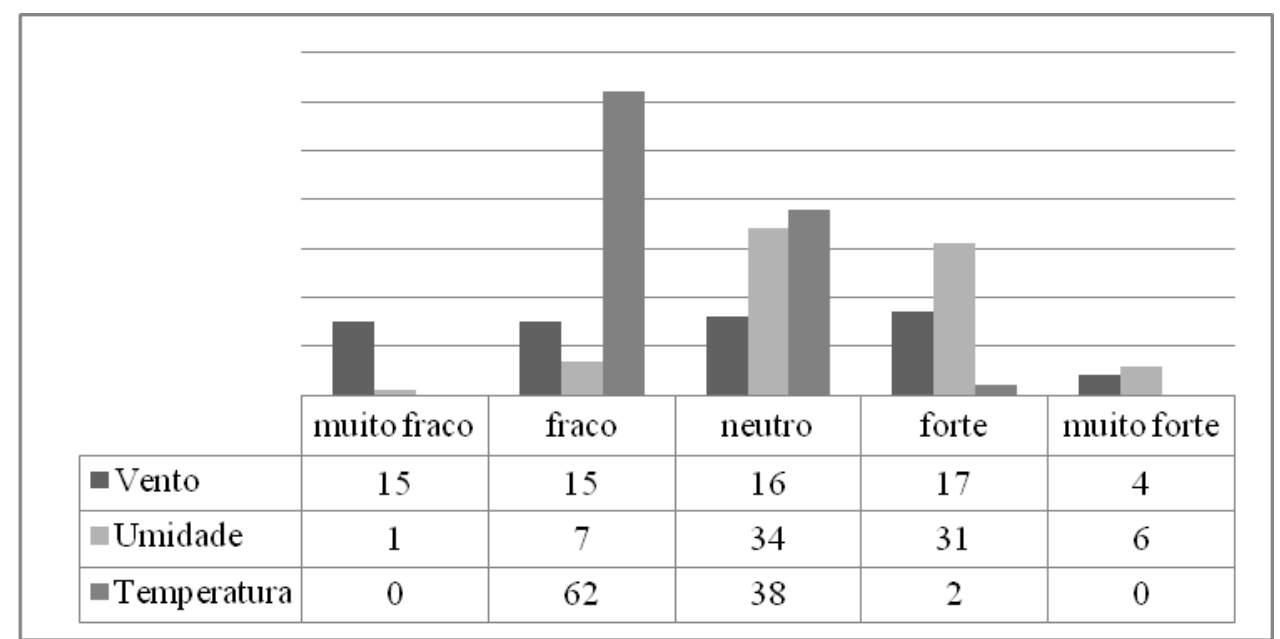

Figura 19 - Percepção do microclima no interior dos fragmentos florestais urbanos para o grupo de indivíduos termicamente confortáveis $(\mathrm{ASV}=0)$

Observa-se que as pessoas percebem o microclima dos bosques mais fresco e mais úmido do que as condições de tempo na ambiência urbana: $90 \%$ dos entrevistados consideraram a temperatura do ar neutra na ambiência urbana, e 75\% dos mesmos entrevistados consideraram a temperatura dos bosques fraca ou fresca. Enquanto $52 \%$ consideraram o ar pouco úmido na ambiência urbana, $50 \%$ consideraram o ar no interior dos bosques nem úmido nem seco.

Esse deslocamento das frequências de votos é evidente para temperatura e umidade, no entanto, em relação ao vento, verifica-se que o deslocamento ocorre de fraco na área urbana (39\%) para vento forte no interior dos bosques (23\%), o que não corresponde aos dados microclimáticos coletados. Essa interpretação errônea indica que as pessoas associam temperatura amena à ventilação e à assimetria de radiação, que é mais intensa nas áreas construídas Associam também a temperatura alta à ausência de vento e à baixa umidade, como foi observado nas entrevistas.

Já para os indivíduos termicamente confortáveis no interior dos bosques $(\mathrm{ASV}=0)$ os votos de sensação térmica concentram-se em temperatura fraca ou amena (42\%), com umidade variando entre neutra (23\%) e forte (21\%), sem um consenso sobre a sensação do vento.

\section{Conforto térmico em fragmentos florestais urbanos}

Foram calculadas as frequências de votos relacionadas a cada categoria de sensação térmica para os índices PMV, PET e ASV, como apresentado na Figura 20. 


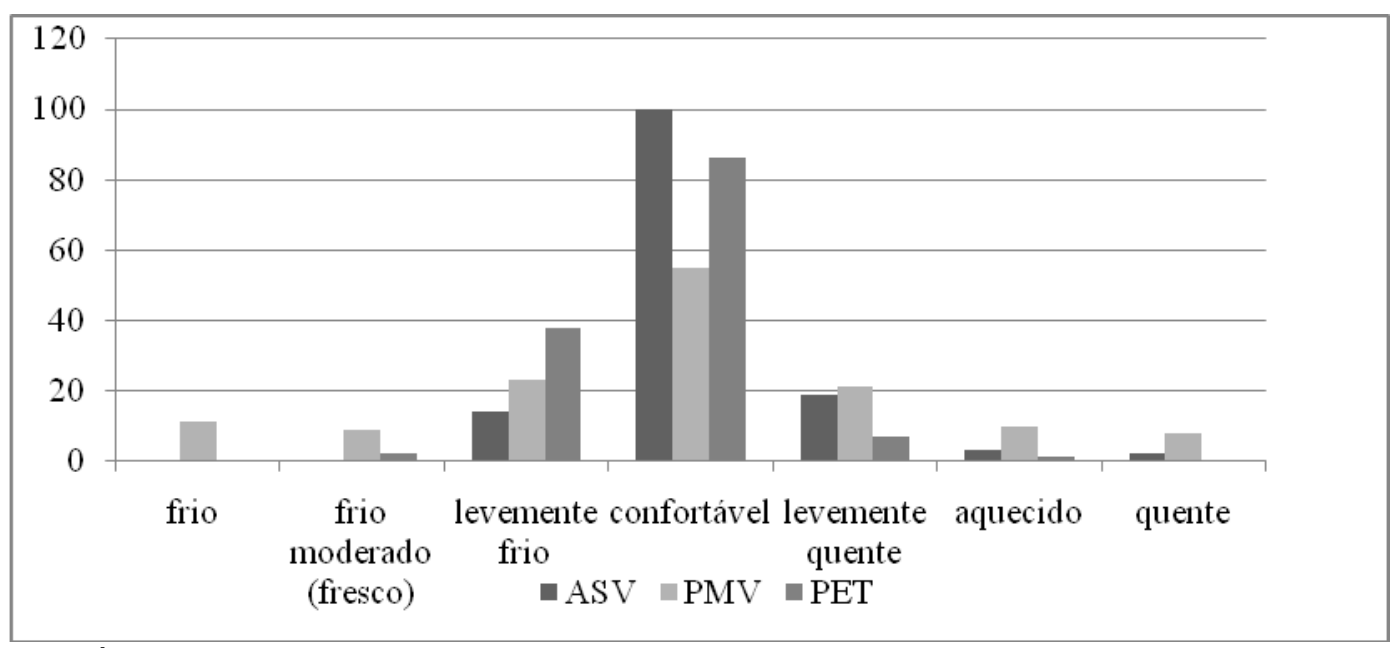

Figura 20 - Índices de conforto térmico e escala de sensação térmica

Verifica-se que a distribuição dos votos segue o mesmo perfil para os diferentes índices, sendo os percentuais mais altos para a sensação de conforto. No entanto, os percentuais de votos para cada categoria variam entre os índices, verificando-se que:

(a) $72,4 \%$ da população afirmaram estar confortáveis;

(b) 63,3\% estavam nessa condição considerandose a faixa da PET entre 18 e $23{ }^{\circ} \mathrm{C}$ (JENDRITZKY et al., 1990 apud MATZARAKIS et al., 1999), e $70,3 \%$ encontravam-se na faixa entre 18 e $26{ }^{\circ} \mathrm{C}$, calibrada por Monteiro e Alucci (2007b) para a cidade de São Paulo; e

(c) $39,8 \%$ estavam dentro da faixa de conforto estimada pelo PMV entre $-0,5$ e $+0,5$.

Como o PMV foi desenvolvido para ambientes estacionários, tendo limites para a oscilação das variáveis ambientais, já era esperado que sua aplicação em espaços abertos se distinguisse dos votos reais dados pelos usuários, apresentando menores percentuais de indivíduos termicamente neutros. O PMV variou entre $-3,7$ (muito frio) e $+3,4$ (muito calor), dada a sensibilidade desse índice à radiação e, consequentemente, em relação à temperatura radiante média, que oscila no interior da floresta entre momentos em que há incidência ocasional de raios solares (flashes de luz) e momentos de sombreamento total, nos quais a temperatura de globo apresenta-se mais baixa que a temperatura do ar. A mediana do PMV foi de $-0,05$ (neutralidade térmica); o $1^{\circ}$ quartil, $0,7^{\circ} \mathrm{C}$; e o $3^{\circ}$ quartil, $-1,075^{\circ} \mathrm{C}$ (leve frio e leve calor), com $50 \%$ da amostra encontrando-se dentro desse intervalo.
Também foi calculada a temperatura operativa, a partir dos dados microclimáticos relacionados a cada indivíduo entrevistado, encontrando-se a maior frequência para $21{ }^{\circ} \mathrm{C}$, e a média, $21,33{ }^{\circ} \mathrm{C}$ (desvio padrão $=2,65)$, como mostra a Figura 21 .

Para um ambiente controlado, e PPD (predicted percentage dissatisfied) $<15 \%$, a ISO 7730 (2005) propõe uma temperatura operativa ótima em torno de $24{ }^{\circ} \mathrm{C}\left(+-2,5{ }^{\circ} \mathrm{C}\right)$, considerando-se para a situação presente a resistência térmica das vestimentas 0,55 clo e uma taxa metabólica média de $75 \mathrm{~W} / \mathrm{m}^{2}$ (um maior número de indivíduos encontrava-se entre $0,58 \mathrm{~W} / \mathrm{m}^{2}$ e $110 \mathrm{~W} / \mathrm{m}^{2}$ ). Portanto, a situação real dos bosques urbanos provê situações de conforto similares a ambientes fechados, porém, como se trata de um espaço aberto, não há estabilidade térmica e a temperatura operativa não segue uma curva normal de distribuição, limitando a aplicação do índice.

Já a temperatura PET, que indica o nível de estresse térmico da população, é condizente com os votos reais dos usuários, ocorrendo uma diferença de apenas $2,1 \%$ dos votos para indivíduos sob condição de neutralidade térmica. Apenas 0,7\% da amostra encontra-se em situações de estresse por calor, e $29 \%$ encontram-se em estresse causado por frio. A PET mínima encontrada foi de $12,1{ }^{\circ} \mathrm{C}$, a máxima, $33,7{ }^{\circ} \mathrm{C}$, a média ocorreu em $19,45{ }^{\circ} \mathrm{C}$, a mediana em $19,15^{\circ} \mathrm{C}$, o $1^{\circ}$ quartil, $12,1^{\circ} \mathrm{C}$, e o $3^{\circ}$ quartil, $21,5^{\circ} \mathrm{C}$ (desvio padrão $=2,99)$. A temperatura PET concentra-se na faixa de $21{ }^{\circ} \mathrm{C}$, como representado na Figura 22, indicando uma situação de equilíbrio fisiológico. 


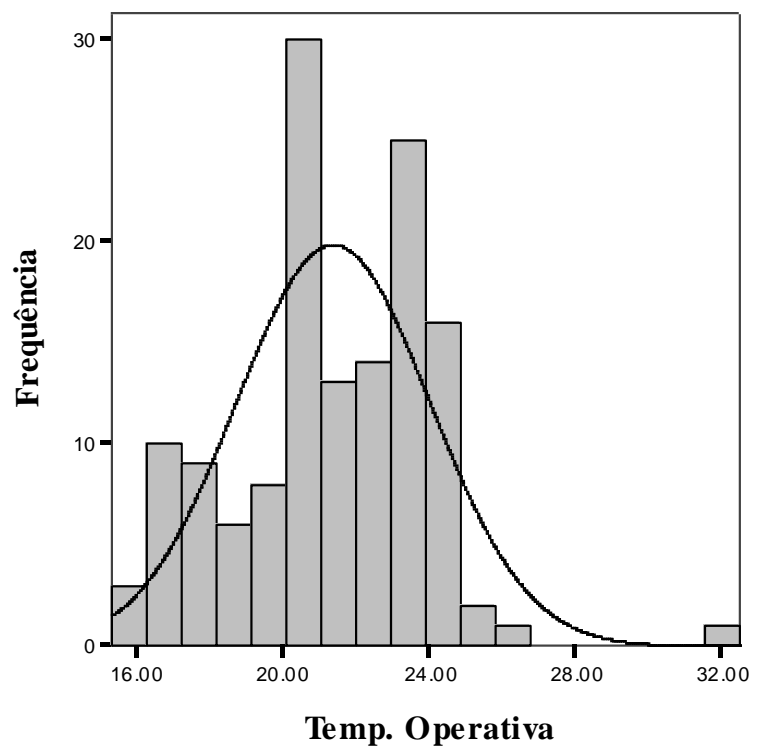

Figura 21 - Frequência da temperatura operativa no interior de fragmentos florestais urbanos

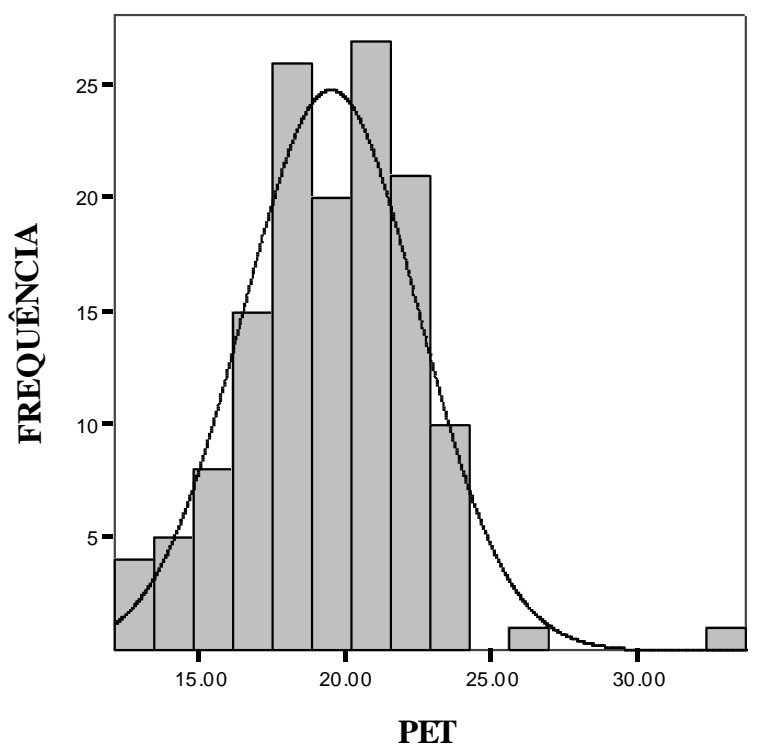

Figura 22 - Distribuição de temperatura PET no interior de fragmentos florestais urbanos

Associaram-se ainda os índices calculados aos votos reais de conforto, conforme representado nas Figuras 23 e 24 . Em ambos os casos, observa-se a tendência de ascensão das medianas com a variação da sensação térmica real, partindo de frio para quente. Analisando-se o grupo de neutros $(\mathrm{ASV}=0)$, verificou-se que a mediana do PMV é 0,1 , e o $1^{\circ}$ e o $3^{\circ}$ quartil (que abrangem $50 \%$ do grupo de neutros) variaram entre $-1 \mathrm{e}+0,7$ (Figura 23); a mediana da temperatura PET para o grupo de neutros foi $19,15^{\circ} \mathrm{C}$, e o $1^{\circ}$ e o $3^{\circ}$ quartil variaram entre 17,5 e $22^{\circ} \mathrm{C}$ (Figura 24$)$.

\section{Percepção ambiental}

Para a avaliação da percepção ambiental foi perguntado sobre:

(a) imagem do lugar: quando você pensa no Bosque ......, o que te vem em mente?

(b) motivos da visita ao local: por que você vem aqui?

(c) frequência de uso: qual a frequência de uso do local?

(d) problemas no local: você nota problemas aqui? Quais?

(e) topofilia: você gosta daqui? Por quê? 


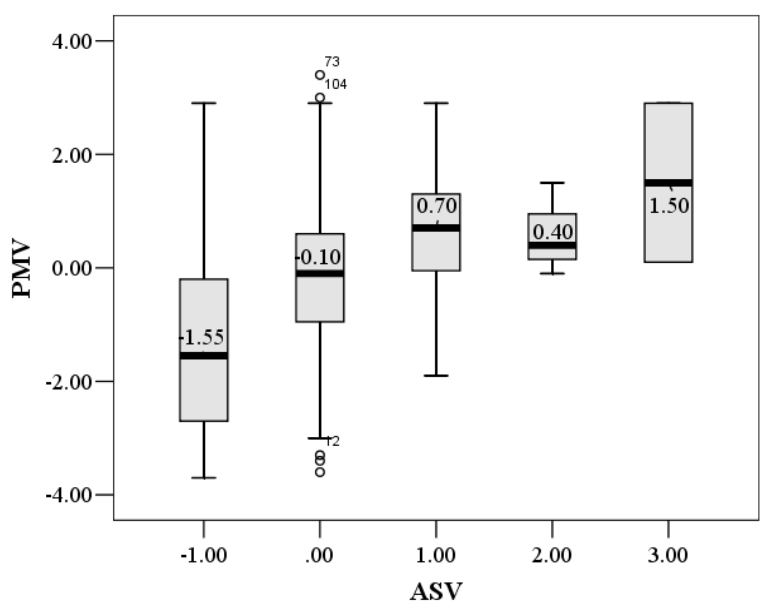

Figura 23 - Boxplot para PMV relacionado ao ASV, calculado no interior de fragmentos florestais urbanos de Campinas

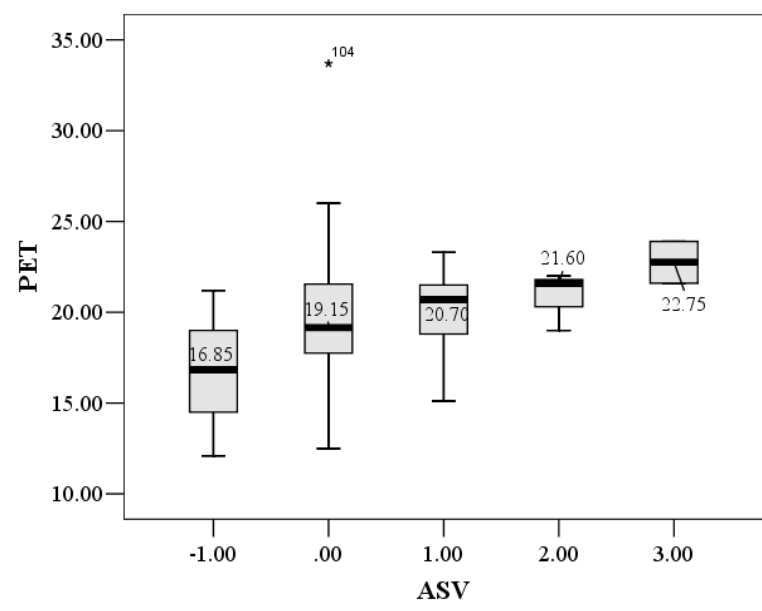

Figura 24 - Boxplot para PET relacionada ao ASV, calculado no interior de fragmentos florestais urbanos de Campinas

\begin{tabular}{|c|c|c|c|c|c|c|c|c|}
\hline \multirow[t]{2}{*}{$\begin{array}{l}\text { Imagem } \\
\text { mental }\end{array}$} & $\begin{array}{l}\text { Natureza } \\
\text { divina, } \\
\text { biofilia }\end{array}$ & $\begin{array}{l}\text { Lazer, } \\
\text { amizade, } \\
\text { recreação, } \\
\text { esportes }\end{array}$ & $\begin{array}{l}\text { Inseguran- } \\
\text { ça, medo, } \\
\text { abandono }\end{array}$ & Memória & $\begin{array}{l}\text { Clima, } \\
\text { saúde, } \\
\text { despoluição }\end{array}$ & $\begin{array}{l}\text { Fruição, } \\
\text { conforto }\end{array}$ & & \\
\hline & $23 \%$ & $7 \%$ & $22 \%$ & $6 \%$ & $5 \%$ & $37 \%$ & & \\
\hline \multirow[t]{2}{*}{$\begin{array}{l}\text { Motivos de } \\
\text { uso }\end{array}$} & $\begin{array}{l}\text { Praticar } \\
\text { exercício }\end{array}$ & Trabalhar & Namorar & $\begin{array}{l}\text { Encontrar } \\
\text { amigos }\end{array}$ & $\begin{array}{l}\text { Brincar, } \\
\text { levar } \\
\text { crianças } \\
\text { para brincar }\end{array}$ & $\begin{array}{l}\text { Descansar, } \\
\text { distrair-se }\end{array}$ & $\begin{array}{l}\text { Está de } \\
\text { passagem } \\
\text { pelo local }\end{array}$ & $\begin{array}{l}\text { Apreciar } \\
\text { elementos } \\
\text { da natureza }\end{array}$ \\
\hline & $20 \%$ & $27 \%$ & $9 \%$ & $24 \%$ & $3 \%$ & $9 \%$ & $5 \%$ & $3 \%$ \\
\hline \multirow{2}{*}{$\begin{array}{l}\text { Frequência } \\
\text { de uso }\end{array}$} & Diária & Semanal & Quinzenal & Mensal & Esporádica & & & \\
\hline & $23,1 \%$ & $30 \%$ & $4,2 \%$ & $8,4 \%$ & $34,3 \%$ & & & \\
\hline \multirow[t]{2}{*}{$\begin{array}{l}\text { Problemas } \\
\text { relacionados } \\
\text { ao espaço }\end{array}$} & $\begin{array}{l}\text { Não nota } \\
\text { problemas }\end{array}$ & $\begin{array}{l}\text { Inseguran- } \\
\text { ça, ausência } \\
\text { de pessoas }\end{array}$ & $\begin{array}{l}\text { Manuten- } \\
\text { ção, equipa- } \\
\text { mentos ina- } \\
\text { dequados } \\
\text { ou ausentes, } \\
\text { programas } \\
\text { de incenti- } \\
\text { vo ao uso }\end{array}$ & Drogas & $\begin{array}{l}\text { Poluição da } \\
\text { água (lago, } \\
\text { córrego), } \\
\text { problemas } \\
\text { ambientais }\end{array}$ & $\begin{array}{l}\text { Iluminação } \\
\text { inadequada }\end{array}$ & $\begin{array}{l}\text { Piso } \\
\text { irregular }\end{array}$ & \\
\hline & $34 \%$ & $16 \%$ & $26 \%$ & $7 \%$ & $12 \%$ & $2 \%$ & $3 \%$ & \\
\hline \multirow[t]{2}{*}{$\begin{array}{l}\text { Afetividade / } \\
\text { vínculo com } \\
\text { o lugar }\end{array}$} & $\begin{array}{l}\text { Natureza, } \\
\text { biofilia }\end{array}$ & $\begin{array}{l}\text { Local de } \\
\text { trabalho }\end{array}$ & $\begin{array}{l}\text { Inseguran- } \\
\text { ça, medo, } \\
\text { abandono }\end{array}$ & $\begin{array}{l}\text { Proximida- } \\
\text { de, oportu- } \\
\text { nidade de } \\
\text { lazer, fami- } \\
\text { liaridade }\end{array}$ & $\begin{array}{l}\text { Tranquili- } \\
\text { dade, paz, } \\
\text { liberdade }\end{array}$ & $\begin{array}{l}\text { Conforto, } \\
\text { local } \\
\text { agradável }\end{array}$ & Segurança & $\begin{array}{l}\text { Outros } \\
\text { motivos }\end{array}$ \\
\hline & $19 \%$ & $25 \%$ & $4 \%$ & $26 \%$ & $1 \%$ & $3 \%$ & $20 \%$ & $2 \%$ \\
\hline
\end{tabular}

Tabela 3 - Percepção dos usuários em relação aos bosques públicos de Campinas

As respostas foram posteriormente reunidas em categorias, formuladas a partir das respostas mais frequentes, calculando-se as frequências como apresentado na Tabela 3 .

O significado dos fragmentos florestais urbanos para a população está relacionado à conservação da natureza e à possibilidade de entrar em contato com ela, encontrando nesses espaços oportunidades para lazer, recreação, prática de atividades físicas e sociabilidade em ambientes familiares, cujos frequentadores, em geral, se conhecem e têm amizade, já que são moradores do mesmo bairro. Esses espaços dão oportunidade para fruição, descanso, conservação da memória cultural, visto que muitos dos visitantes adultos frequentaram os locais quando criança. O microclima propiciado pela densa arborização é percebido positivamente pelos usuários, que valorizam o ar puro, o sombreamento e o ar fresco, contrapondo-se a ambiência do fragmento florestal 
à ambiência comum dos espaços públicos urbanos (onde há congestionamentos de veículos, poluição do ar, calor, alta taxa de radiação, poluição sonora, etc.). Por outro lado, a "floresta" é também lugar do medo e da insegurança, pela baixa permeabilidade visual e presença eventual de pessoas marginalizadas. A população reconhece problemas tais como a insegurança causada pela presença de estranhos, baixa densidade de usuários, ausência de programas do governo que incentivem a prática de esportes e recreação, falta de manutenção e conservação física dos espaços e dos equipamentos comunitários, e ausência de ações para a preservação ambiental. Apesar dos problemas percebidos pelos usuários em relação à conservação, manutenção e insegurança, prevalece a sensação de conforto nesses espaços, relacionados possivelmente à afetividade ou topofilia, visto que $99,3 \%$ dos indivíduos entrevistados gostam dos bosques.

\section{Conclusão}

Comparando-se o microclima de cinco bosques públicos de Campinas aos dados da estação meteorológica em três estações do ano, conclui-se que a vegetação densa e estratificada é capaz de atenuar a temperatura do ar, interceptar a radiação solar e manter a velocidade do ar em baixa amplitude, caracterizando ventos leves na Escala Beaufort. A umidade absoluta do ar é mais baixa nos bosques do que na estação meteorológica, mas, provavelmente, é maior do que nas ambiências urbanas, devido à evapotranspiração que ocorre nas áreas verdes.

Foi aplicado um questionário para a avaliação da sensação térmica e de conforto em espaços externos, baseando-se no modelo RUROS europeu e complementando-o com questões que envolvem a ciência cognitiva. Um encadeamento de perguntas, que parte de uma escala espacial e temporal mais ampla para uma situação mais específica, auxiliou os indivíduos entrevistados a darem uma resposta consciente em relação à percepção do microclima e de conforto térmico. Ainda assim, notaram-se associações por parte dos entrevistados que não correspondem aos dados microclimáticos observados, tais como considerar o vento forte quando a temperatura está amena, ou considerar a umidade baixa quando a temperatura do ar na cidade está alta. Em geral, os bosques públicos são percebidos como locais confortáveis, o que é atribuído à presença da natureza. Seu microclima é relativamente estável ao longo das estações, o que é positivo para a adaptação térmica humana, verificando-se que a população mantém um padrão de vestimenta ao longo das estações.
Os usuários mais frequentes dos bosques públicos são moradores dos bairros próximos, que têm uma relação afetiva com os locais, utilizando-os para atividades físicas, encontro de amigos, trabalho e fruição. A manutenção, vigilância e programas públicos de educação ambiental, cultura e esportes são solicitados pela população, que se preocupa com a ocupação efetiva e com a conservação do patrimônio natural.

Os índices de conforto PMV e PET confirmam a prevalência do conforto térmico no interior dos bosques. A PET, mais apropriada para espaços abertos, mostrou boa correlação com os votos de conforto obtidos por meio de questionários, confirmando o intervalo proposto por Jendritzky et al. (1990) e calibrado por Monteiro e Alucci (2007b) para São Paulo. Já os percentuais das classes de conforto calculados pelo PMV não condizem com a situação declarada pelos entrevistados, apesar de o índice ser relativamente aplicável na situação microclimática em questão.

\section{Referências}

BRASIL. Lei n. 4771, de 15 de setembro de 1965. Institui o Novo Código Florestal. Brasília, DF, 1965.

\section{BRASIL. Lei n. 6766, de 19 de dezembro de} 1979. Dispõe sobre o Parcelamento do Solo Urbano e dá outras providências. Brasília, DF, 1979.

BRASIL. Ministério da Agricultura, Pecuária e Abastecimento. Empresa Brasileira de Pesquisa Agropecuária (EMBRAPA). Comunicação Técnica 26: formação do bosque do quilombo da Embrapa monitoramento por satélite. Campinas, 2008.

BRUSANTIN, G. N.; FONTES, M. S. G. C. Conforto Térmico em Espaços Públicos de Permanência: uma experiência na cidade de BauruSP. In: ENCONTRO NACIONAL, 10., ENCONTRO LATINO AMERICANO DE CONFORTO NO AMBIENTE CONSTRUÍDO, 6., 2009, Natal. Anais... Porto Alegre: ANTAC, 2009. p. 441-449.

BUENO-BARTHOLOMEI, C. L.; LABAKI, L. C. How Much does the Change of Species of Trees Affect their Solar Radiation Attenuation? In: INTERNATIONAL CONFERENCE ON URBAN CLIMATE, 5., 2003, Lodz. Proceedings.... Lodz: IAUC, 2003. v. 1. p. 267-270. 
CAMPINAS. Prefeitura Municipal. Secretaria de Planejamento e Meio Ambiente (SEPLAMA). Lei Complementar $n^{\circ} 15$, de 27 de dezembro de 2006. Dispõe sobre o Plano Diretor do Município de Campinas. Campinas, 2006.

CASTRO, L. L. F. de LIMA. C. Estudo de Parâmetros de Conforto Térmico em Áreas Verdes Inseridas no Ambiente Urbano. Dissertação (Mestrado em Engenharia Civil) Universidade Estadual de Campinas. Campinas, UNICAMP, 1999.

\section{CENTRO DE PESQUISAS \\ METEOROLÓGICAS E CLIMÁTICAS} APLICADAS A AGRICULTURA (CEPAGRI). Dados Diários do Clima de Campinas (obtidos diretamente na CEPAGRI) e Dados Médios do Clima de Campinas entre Junho de 1998 e Outubro de 2008. Campinas, 2009. Disponível em: http://www.cpa.unicamp.br/index.html. Acesso em: 04 dez. 2009.

DACANAL, C. et al. Conforto Térmico em Espaços Livres Públicos: estudo de caso em Campinas, SP. In: ENCONTRO NACIONAL, 10., ENCONTRO LATINO AMERICANO DE CONFORTO NO AMBIENTE CONSTRUÍDO, 6., 2009, Natal. Anais... Porto Alegre: ANTAC, 2009. p. 563-572.

DUBOIS, D.; DUBOIS E.F. A formula to Estimate the Approximate Surface Area if Height and Weight be Known. Archives of Internal Medicine, Chicago, v. 17, p. 863-871, 1916.

FANGER, P. O. Thermal Comfort, Analysis and Applications in Environmental Engineering. New York: McGraw-Hill, 1972.

FONTES, M. S. G. C.; ALJAWABRA, F.; NIKOLOPOULOU, M. Open Urban Spaces Quality: a study in a historical square in Bath UK. In: CONFERENCE ON PASSIVE AND LOW ENERGY ARCHITECTURE, 25., 2008, Dublin. Proceedings... Dublin: University College Dublin, 2008. 1 CD-ROM.

GOMES, M. A. S.; AMORIM, M. C. C. T. Arborização e Conforto Térmico no Espaço Urbano: estudo de caso nas praças públicas de Presidente Prudente (SP). Caminhos de

Geografia, Uberlândia, v. 7, n. 10, p. 94-106, set. 2003. Disponível em:

<http://www.caminhosdegeografia.ig.ufu.br/includ e/getdoc.php?id=295\&article $=78 \&$ mode $=$ pdf $>$. Acesso em: 13 mar. 2009.

HÖPPE, P. Comfort Requirements in Indoor Climate. Energy and Buildings, Lausanne, v. 11, p. 249-257, 1988.
HÖPPE, P. Different Aspects of Assessing Indoor and Outdoor Thermal Comfort. Energy and Buildings, Lausanne, v. 34, p. 661-665, 2002.

HÖPPE, P. Heat balance modelling. Experientia, Basel, v. 49, p. 741-746, 1993.

HÖPPE, P. The Physiological Equivalent Temperature: a universal index for the biometeorological assessment of the thermal environment. International Journal of Biometeorology, Lisse, v. 43, p. 71-75, 1999.

INTERNATIONAL ORGANIZATION FOR STANDARDIZATION (ISO). ISO 7730:

ergonomics of the thermal environment: analytical determination and interpretation of thermal comfort using calculation of the PMV and PPD indices and local thermal comfort criteria. Geneva, 2005.

JACOBS, J. Morte e Vida de Grandes Cidades. São Paulo: Martins Fontes, 2000.

JENDRITZKY G.; SCHIRMER H.; MENZ G.; SCHMIDT-KESSEN W. Methode zur raumbezogenen Bewertung der thermischen Komponente im Bioklima des Menschen (Fortgeschriebenes Klima-Michel-Modell). Beiträge Akad Raumforschung Landesplanung Hannover, 114, p. 7-69, 1990.

LABAKI, L. C. et al. Thermal Comfort in Outdoor Spaces: the role of vegetation as a means of controlling solar radiation. In: INTERNATIONAL CONFERENCE ON PASSIVE AND LOW ENERGY ARCHITECTURE, 17., 2000, Cambridge. Proceedings... London: James \& James, 2000. v. 1. p. 501-505.

LIN, T. P. Thermal Perception, Adaptation and Attendance in a Public Square in Hot and Humid Regions. Building and Environment, Oxford, v. 44, p. 2017-2026, 2009.

LYNCH, K. A Imagem da Cidade. Tradução de Jefferson Luiz Camargo. São Paulo: Martins Fontes, 1997

MATZARAKIS, A.; MAYER, H.; IZIOMON, M. G. Applications of a Universal Thermal Index: physiological equivalent temperature.

International Journal of Biometeorology, Lisse, v. 43, p. 76-84, 1999.

MATZARAKIS, A.; RUTZ, F.; MAYER, H. 2006: modelling the thermal bioclimate in urban areas with the RayMan Model. In: INTERNATIONAL CONFERENCE ON PASSIVE AND LOW ENERGY ARCHITECTURE, 23., 2006, Genève. Proceedings... Genève: Université de Genève, 2006. v. 2, p. 449-453. 
MILLER, R. W. Urban Forestry: planning and managing urban greenspaces. 2. ed. Long Grove: Waveland, 2007.

MONTEIRO, L. M.; ALUCCI, M. P. Conforto Térmico em Espaços Abertos com Diferentes Abrangências Microclimáticas: parte 1: verificação experimental de modelos preditivos. In: ENCONTRO NACIONAL, 9., ENCONTRO LATINO AMERICANO DE CONFORTO NO AMBIENTE CONSTRUÍDO, 5., 2007, Ouro Preto. Anais... Porto Alegre: ANTAC, 2007a. p. 1221-1230.

MONTEIRO, L. M.; ALUCCI, M. P. Conforto Térmico em Espaços Abertos com Diferentes Abrangências Microclimáticas: parte 2: proposição de calibração de modelos preditivos. In: ENCONTRO NACIONAL, 9., ENCONTRO LATINO AMERICANO DE CONFORTO NO AMBIENTE CONSTRUÍDO, 5., 2007, Ouro Preto. Anais... Porto Alegre: ANTAC, 2007b. p. 1231-1240.

MONTEIRO, L. M.; ALUCCI, M. P. Calibration of Outdoor Thermal Comfort Models. In: INTERNATIONAL CONFERENCE ON PASSIVE AND LOW ENERGY

ARCHITECTURE, 23., 2006, Genève. Proccedings... Genève: Université de Genève, 2006. p. 515-522.

NATIONAL CENTRE FOR SOCIAL RESEARCH (EKKE). RUROS: rediscovering the urban realm and open spaces 2002-2003. Athens: EKKE, 2004. Final Project Report.

NIKOLOPOULOU, M.; LYKOUDIS, S. Thermal Comfort in Outdoor Urban Spaces: analysis across different European countries. Building and

Environment, Oxford, v. 41, p. 1455-1470, 2006.

NIKOLOPOULOU, M.; LYKOUDIS, S.; KIKIRA, M.; Thermal Comfort in Outdoor Spaces: field studies in Greece. In: INTERNATIONAL CONFERENCE ON URBAN CLIMATE, 5., 2003, Lodz, Poland. Proccedings... Lodz: WMO, 2003. 1 CD-ROM.
NIKOLOPOULOU, M.; STEEMERS, K. Thermal Comfort and Psychological Adaptation as a Guide for Designing Urban Spaces. Energy and Buildings, Lausanne, v. 35, p. 95-101, 2003.

NIKOLOPOULOU, M. H.; BAKER, N.; STEEMERS, K. Thermal Comfort in Outdoor Urban Spaces: Understanding the Human Parameter. Solar Energy, Kidlinton, v. 70, n. 3, p. 227-235, 2001.

OKE, T. R. Initial Guidance to obtain Representative Meteorological Observations at Urban Sites. Geneva: WMO, 2006. (Instruments and Observing Methods Report, n. 81).

RESERVA DA BIOSFERA DA MATA ATLÂNTICA (RBMA). São Paulo, c2009.

Disponível em: <http://www.rbma.org.br>. Acesso em: 05 dez. 2009.

SHIMAKAWA, A. H.; BUENO-

BARTHOLOMEI, C. L. Aplicação dos Modelos Preditivos de Conforto PET e PMV em Presidente Prudente - SP: estudo de caso: Parque do Povo. In: ENCONTRO NACIONAL, 10., ENCONTRO LATINO AMERICANO DE CONFORTO NO AMBIENTE CONSTRUÍDO, 6., 2009, Natal. Anais... Porto Alegre: ANTAC, 2009. p. 543-552.

SPAGNOLO, J.; DE DEAR, R. A Field Study of Thermal Comfort in Outdoor and Semi-Outdoor Environments in Subtropical Sydney Australia. Building and Environment, Oxford, v. 38, p. 721-738, 2003.

TUAN, Y. F. Espaço e Lugar. São Paulo: DIFEL, 1983.

TUAN, Y. F. Topofilia: um estudo da percepção, atitudes e valores do meio ambiente. São Paulo: DIFEL, 1980.

UNIVERSITÄT FREIBURG. Meteorologisches Institut. RayMan. Version 1.2. Freiburg, 2009.

Disponível em:

<http://www.urbanclimate.net/rayman/index.htm>. Acesso em: 13 ago. 2009.

\section{Agradecimentos}

Os autores agradecem à CAPES pela bolsa de auxílio à pesquisa. 